\title{
Application and Analysis of Education and Teaching Mode Based on 5G and Smart Technology
}

\author{
Ran Yan \\ School of Marxism, Zhengzhou Railway Vocational \& Technical College, ZhengZhou 451460, China \\ Correspondence should be addressed to Ran Yan; 11110@zzrvtc.edu.cn
}

Received 5 November 2021; Revised 6 December 2021; Accepted 14 December 2021; Published 13 January 2022

Academic Editor: Le Sun

Copyright ( $\odot 2022$ Ran Yan. This is an open access article distributed under the Creative Commons Attribution License, which permits unrestricted use, distribution, and reproduction in any medium, provided the original work is properly cited.

\begin{abstract}
The development of information technology has brought tremendous changes to our country's education. Based on the $5 \mathrm{G}+$ Internet, the article proposes a brand-new intelligent education model and proposes an ST analysis method, which mainly studies the teacher and students in the classroom. Class performance, based on Yebes network, proposed a learning decision method and application. The research results of the article show the following: (1) The article compares the monthly test scores of three variables under two different teaching modes. The results show that the performance of the online teaching mode is generally better than that of the traditional teaching mode, and the performance of the experimental class has increased more, with an average growth score of 4.83 , indicating that there are significant differences in students' learning and cognitive abilities under different teaching models. (2) The article compares the students' knowledge mastery under two different teaching modes. The results show that under the traditional teaching mode, the students' knowledge mastery is low, and the complete mastery rate is only $15 \%$. In the network multimedia teaching mode, the students' knowledge mastery rate has been greatly improved, the complete mastery rate is as high as $45 \%$, and the students' mastery of knowledge has been extremely improved, indicating that the network multimedia teaching mode can stimulate students' learning interest more, improve learning efficiency. (3) Studying the differences in the source of curriculum resources of three different types of teachers, and the results show that the proportion of curriculum resources downloaded through the Internet is the largest; in the investigation of the impact of multimedia teaching on the classroom, the cooperation rate of students when multimedia teaching is not used, classroom practice accuracy and classroom completion rate are low, but after using multimedia teaching, students' cooperation rate and classroom practice accuracy rate have been greatly improved, among which the accuracy rate of the experimental class is as high as $62.4 \%$, and the students' thinking ability is also good. Great improvement.
\end{abstract}

\section{Introduction}

Information technology has brought tremendous changes to China's education. $5 \mathrm{G}$ technology has provided a better guarantee for the sharing of curriculum resources. In the face of the extreme shortage of education resources in China, limited educational resources, and unlimited higher education development needs the contradiction between them is becoming more and more prominent. How to effectively realize the resource sharing among various universities has become a problem that must be considered in the development of talents in major universities. Literature [1] explores teaching models suitable for teaching activities. Literature [2] describes the implementation process of the model in educational statistics and SPSS courses. The article analyzes the implementation process of the teaching model from the aspects of experiment and evaluation and puts forward the problems and solutions in the application process of the model. Literature [3] constructs a smart classroom teaching model that conforms to the development of the times by analyzing the connotation and technical characteristics of smart classrooms. Network technology has gradually replaced traditional learning methods. Some e-learning platforms have also received more and more people's favor. Some educational structures are also taking full advantage of the advantages of e-learning to attract more people. Literature [4] mainly describes how to 
identify and analyze factors that contribute to the design of e-learning applications. Literature [5] mainly discusses the application of modern educational technology in computer teaching. On university campuses, using the convenience of $5 \mathrm{G}$ and the Internet, they have gradually formed a model of curriculum education resource sharing, which can share teaching resources, as well as the sharing of teacher resources, curriculum resources, and advanced teaching facilities. Literature [6] is based on the DBR educational research paradigm and verifies the original concept through practical exploration in real situations. Literature [7] conducted a series of data analyses and research on the application of data mining technology in student performance. Analyzed the internal relations and teaching rules between the various courses. With the advent of the Internet age, the use of big data analysis technology has become a method and technology used in many fields, and big data has also promoted the reform and innovation of various universities. With the development of science and technology and the prevalence of Internet technology, compared with traditional networks, 5G networks have the advantages of low coverage, low energy consumption, and high capacity in hot spots. It can carry out data dissemination very well. According to the current state of extreme scarcity of educational resources, some places do not have advanced teaching resources, and it is necessary to use the convenience of the Internet to communicate and share on the Internet. Literature [8] starts from the design concept of the smart campus and studies the application of data mining technology in the smart campus system under the background of big data. Literature [9] analyzes the characteristics and advantages of the university listening and speaking teaching mode under the network environment. Literature [10] analyzed the advantages of the experimental teaching platform in terms of hardware and software and designed the application mode of the PBL teaching method in the experimental teaching platform. Literature [11] conducts a rational analysis of the application of information technology in education, based on the mainstream technological phenomenology of the current philosophy of technology. With the development of Internet technology, the demand for technical talents is also increasing. In order to cultivate more professional talents, a model of integration of production and education can be implemented. Literature [12] makes a general analysis of the application of intelligent technology in teaching mode at the present stage in China and discusses the current situation of the application of talent training mode. Literature [13] analyzes the sports teaching mode based on multimedia information technology and the advantages of multimedia teaching from the perspective of $5 \mathrm{G}$ and the internet of things technology. Literature [14] investigates the education mode of a university and analyzes the teaching elements of innovative teaching of numerical control technology application from the teaching case analysis. Literature [15] proposed a new mobile platform for micro-English education and learning based on mobile 5G technology.

\section{Basic Theory}

2.1. The Application of 5G Smart Technology in Education. $5 \mathrm{G}$ is the foundation of the intelligent Internet. In the teaching process, it is equipped with information technology such as remote interaction and artificial intelligence, which is deeply integrated with course teaching, enriches classroom teaching, allows students to participate in teaching, and enhances students' interest in learning. Teachers can teach students in accordance with their aptitude through real-time interaction with students. Many excellent teaching resources can be shared on the Internet; through the Internet, students can study outside of class, check deficiencies, and realize the universalization of education. Even in the most remote rural areas, as long as they have the Internet, they can enjoy rich and high-quality education. Resources, to achieve the sharing of educational resources. In the field of education, $5 \mathrm{G}+\mathrm{Al}$ will give birth to intelligent education, embodying a people-oriented teaching model. Through the close integration of $\mathrm{Al}$ and big data technology, under the support of $5 \mathrm{G}$ network, the teaching data related to the teaching behavior of the teacher in the classroom and the student's listening effect are captured in real-time through the intelligent teaching terminal, and the method and method of the teacher's teaching in the teaching are extracted by using big data analysis technology. Based on the unstructured behavior data generated by the students' listening state, the extracted unstructured data is effectively analyzed and summarized with the help of AI algorithms, cloud computing, etc., and finally using data visualization technology, according to the data results generated by teachers and students, teaching managers, teachers, and students provide scientific behavior analysis reports, which are displayed to relevant teaching management institutions and class teachers to assist teaching management and improve teaching quality. For parents, they can observe students' learning conditions online, realize online tutoring, and protect their children's healthy growth. The application of $5 \mathrm{G}$ in the education industry is shown in Figure 1:

$5 \mathrm{G}$ and intelligent technology have brought a lot of convenience to the work and study of teachers and students. Intelligence means that the campus has a scientific research cloud, intelligent classroom, campus security, and other platforms. Teachers can read papers online and evaluate oral English. Students can also learn online, and parents can tutor online; the platform will introduce student information and teaching resources into the platform. The intelligent technology + education will further extend the information interconnection from the breadth to the colleges and universities, from the depth to the organization of colleges and universities, and smooth informatization.

2.2. Construction of Intelligent Education Model. The development model of the smart education resource innovation ecosystem is the progression and deepening of the "Internet +" education development model and is the product of smart technology + education resources. Internet education takes communication and social interaction as the 


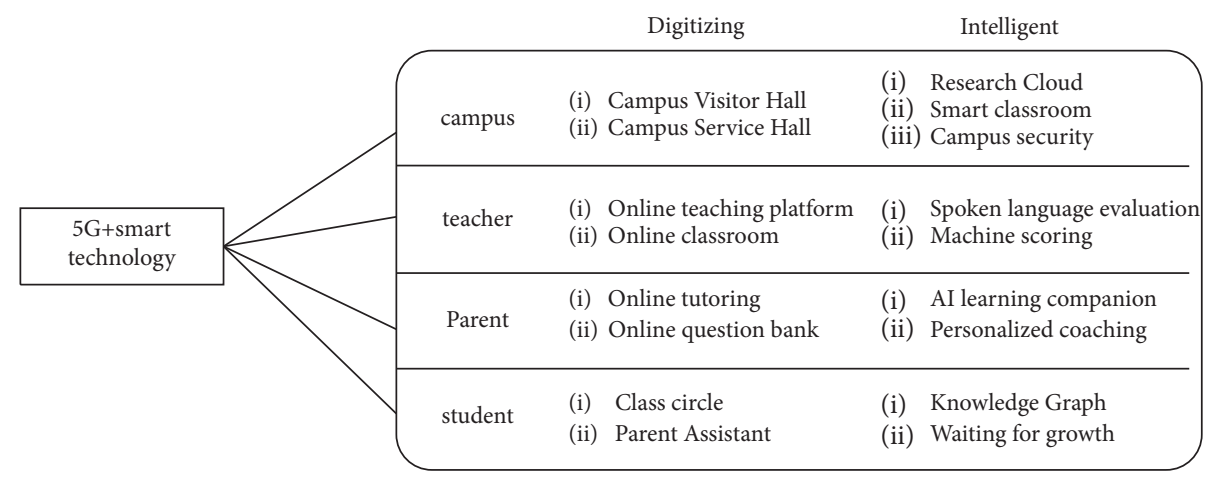

Figure 1: 5G + smart technology helps education.

core content, realizes the connection between learners, and establishes a learning website, connects learners and campus services, that is, establishes external connections between learners and campus, and makes the campus service information communicated to learners more efficiently and quickly. The intelligent technology + education will further extend the information interconnection from the breadth to the various colleges and universities, from the depth to the internal organization of the colleges, and smooth informatization, so that the school can reorganize the learning elements and the needs of the learners. The management operation mode, so as to achieve efficient coordination between learners and school management operations, and more efficient matching of information supply and demand. The intelligent education model diagram is shown in Figure 2:

The development mode of the intelligent education resources innovation ecosystem is progressive and deepening of the "Internet +" education development mode and is the product of intelligent technology+education resources. Internet education takes communication and social interaction as the core content, realizes the connection between learners, and establishes a learning website to connect learners and campus services, that is to establish the external connection between learners and campus so that the service information of campus can be more efficiently and quickly conveyed to learners. The new ecosystem of intelligent education provides services for learners. Learners feedback data to the new ecosystem of intelligent education, and the information fed back can generate educational resources through the new ecosystem.

2.3. Analysis of Intelligent Teaching Mode. Based on the 5G mobile network, it is possible to achieve lectures by famous teachers in the near-end classrooms, interaction, auditing, and commenting in the remote classrooms, and to achieve smooth listening and free evaluation in campus scenarios such as remote recording and broadcasting classrooms, dual-teacher classrooms, and smart classroom delivery. Classes, centralized control, 5G remote listening, and evaluation classes have greatly improved in response speed, image quality, feedback timeliness, and evaluation effectiveness. Realize online patrol realize the diversification of teaching evaluation. Supported by the
5G network environment, teaching evaluation collects a full range of data through the observation of learners' online or offline learning process, discovers their participation in learning behavior patterns, excavates their thinking process to complete tasks, discovers problems in real-time, and solves the process. In order to realize the real-time and accurate evaluation of the problems encountered in the process and the formulation of intervention methods, the realization of multimodal learning data collection, full-scene demand analysis, and threedimensional evaluation, and realization of guidance and improvement based on the results of learning evaluation. The intelligent education model diagram is shown in Figure 3:

2.3.1. Personalized Learning Mode. Teaching should pay attention to teaching students in accordance with their aptitude because each student's learning methods and mastery of knowledge are different. Personalized education is based on the current learning status of each student to implement education in a targeted manner. With more and more student and learning data recorded by the system, it is more difficult to achieve targeted and personalized education. Intelligent teaching solves this problem very well. The system will conduct a test on the students' learning situation and difficult points, and the test results will be transmitted to the teacher's computer. The teacher can customize the learning plan according to each person's situation. Students can also master their learning situation, so as to carry out targeted exercises, and truly teach students in accordance with their aptitude.

2.3.2. Diversified Learning Modes. The traditional teaching method is basically in a fixed place, teaching according to fixed textbooks, and teachers will teach fixed content according to the requirements of the school. This traditional teaching mode will be restricted by time, place, and space. With the development of science and technology, the new educational model can break the shackles of this traditional teaching concept. Teaching is not limited by time and place and realizes "learning all the time." Students can choose to learn effectively according to their own learning progress and learning intensity. Learning should be people-oriented 


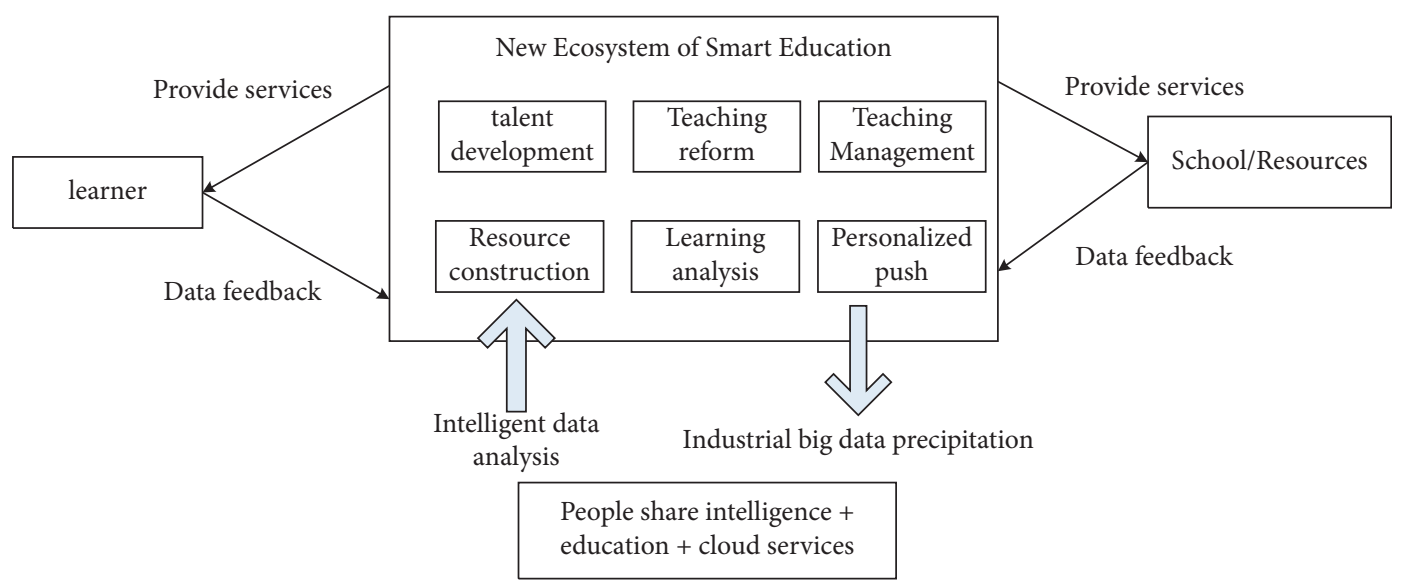

FIGURE 2: Smart education system model diagram.

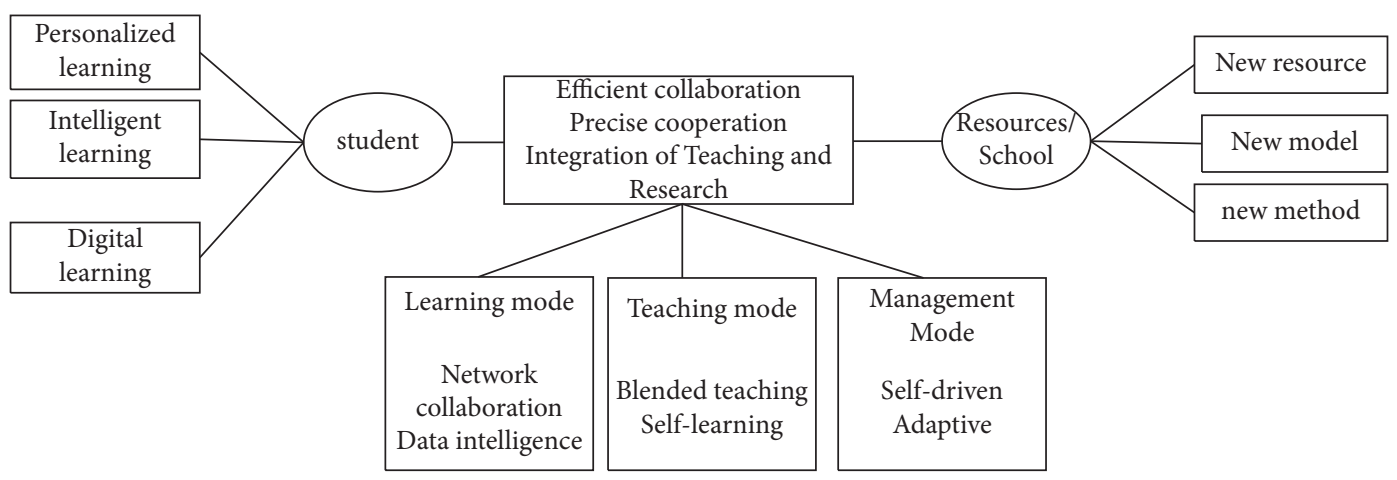

FIgURE 3: Smart education model diagram.

and focus on content rather than form, so as to keep pace with the times.

Differentiated learning is an individualized teaching method, in which teachers adjust the teaching process and products according to students' learning willingness, interest, and learning style. Its learning plan focuses on content, while the learning content of all students remains the same. It is a school- and curriculum-centered approach that attempts to modify the way that is content is taught to meet student needs, differing strengths, and general readiness. Personalized learning looks at the learner, thinking about the question, "What does this student need to know, and how best to do that?" It is a student-centered approach to learning that is built around recognizing the vast differences between students, not only in literacy or diagramming abilities but also in the real needs of students.

\section{Method}

\subsection{Classroom Teaching Analysis}

3.1.1. S-T Analysis Method. S stands for student and Tstands for the teacher. It mainly studies the classroom observation methods of teacher and student behavior in the classroom. The number of $S$ behaviors is recorded as $N_{s}$, and the number of $T$ behaviors is recorded as $N_{t}$ [16], and the formula is

$$
N=N_{s}+N_{t}
$$

The teacher behavior share $R_{t}$ is

$$
\begin{aligned}
R_{t} & =\frac{N_{t}}{N} \\
& =\frac{\left(N-N_{s}\right)}{N} \\
& =1-\frac{N_{s}}{N} .
\end{aligned}
$$
$\mathrm{Ch}$ is

The formula for calculating behavioral conversion rate

$$
\mathrm{Ch}=\frac{g-1}{N}
$$

$\mathrm{Ch}$ is the behavior conversion rate indicates the interactivity in teaching. The larger the $\mathrm{Ch}$, the more frequent the switching between student and teacher behaviors.

3.1.2. Classroom Video Feature Extraction. The convolutional layer is the most common method for deep neural networks to process pictures, which mainly compresses and extracts features [17]; its mathematical formula is 
$S(m, n)=(f * g)(m, n)=\sum_{i=-\infty}^{\infty} \sum_{j=-\infty}^{\infty} f(i, j) g(m-i, n-i)$.

The convolution in the neural network is

$S(m, n)=(I * K)(m, n)=\sum_{i} \sum_{j} I(m+i, n+i) K(i, j)$.

Logical function

$$
s(x)=\frac{1}{1+e^{-x}} .
$$

The hyperbolic tangent function is

$$
\tanh (x)=\frac{e^{x}-e^{-x}}{e^{-x}+e^{-x}}
$$

The linear rectification function is

$$
\operatorname{ReLU}(x)= \begin{cases}0, & x<0 \\ x, & x \geq 0\end{cases}
$$

The function of the normalized index layer is to complete the calculation of the normalized index function in most linear classifiers [18], the specific algorithm input vector is

$$
X=\left(x_{1}, x_{2}, \ldots, x_{n}\right) .
$$

Calculate $n$ scalar values

$$
y_{k}=\frac{e^{x_{k}}}{e^{x_{1}}+\cdots+e^{x_{n}}} .
$$

Spliced into

$$
Y=\left(y_{1}, y_{2}, \ldots, y_{n}\right) .
$$

The pros and cons of the face detection algorithm and the face detection system performance are mainly evaluated by the following main performances [19], the detection rate is

$$
\mathrm{DR}=\frac{m_{1}}{M_{1}} .
$$

False detection rate is

$$
\operatorname{FAR}=\frac{m_{2}}{M_{2}} .
$$

Missed detection rate is

$$
\operatorname{FRR}=\frac{m_{3}}{M_{3}} .
$$

\subsection{Research on the Learning Method of Bayesian Network}

3.2.1. Definition of Bayesian Network. Given a directed acyclic graph $G$, the variable nodes in the graph are a set of discrete variables [20]

$$
U=\left\{X_{i}, X_{2}, \ldots, X_{n}\right\}
$$

The value range of each variable $X_{i}$ is expressed as

$$
\operatorname{Val}\left(X_{i}\right)=\left\{x_{i}^{1}, x_{i}^{2}, \ldots, x_{i}^{m}\right\} .
$$

The conditional probability corresponding to the variable $X_{i}$ is

$$
\theta_{i}=\prod_{i} p\left(x_{i} \mid p a\left(x_{i}\right),\right.
$$

where $p a\left(x_{i}\right)$ is the direct parent node of $x_{i}$, and the joint probability distribution is $p$ [21]

$p\left(x_{i}, x_{2}, \ldots x_{n}\right)=\prod_{i} p\left(x_{i} \mid x_{1}, x_{2}, \ldots, x_{n-1}\right)=\prod_{i} p\left(x_{i} \mid p a\left(x_{i}\right)\right)$.

The pair $\langle G, \Theta\rangle$ formed by the directed acyclic graph $G$ and the parameter set $\Theta=\left\{\theta_{1}, \theta_{2}, \ldots, \theta_{n}\right\}$ becomes a Bayesian network [22].

3.2.2. Bayesian Network Structure Learning. The K2 algorithm mainly solves the problem of network structure learning with unknown structures and complete data [23]. The scoring method is expressed as follows:

$\max _{B s}[P(B s, D)]=C \prod_{i=1}^{n} \max _{\prod i}\left[\prod_{j=1}^{q_{j}} \frac{\left(\left(r_{i}-1\right)\right) !}{\left(N_{i j}+r_{i}-1\right) !} \prod_{k=1}^{r_{i}} N_{i j k} !\right]$.

The $B$ De scoring formula is

$p(G \mid D)=p(G) \prod_{i=1}^{n} \prod_{j=1}^{q_{j}} \frac{\left(\sum_{k} N_{i j k}{ }^{\prime}\right)}{\left(\sum_{k} N_{i j k}{ }^{\prime}+N_{i j}\right)} \prod_{k=1}^{r_{i}} \frac{\left(\sum_{k} N_{i j k}{ }^{\prime}+N_{i j k}\right)}{\left(\sum_{k} N_{i j k}{ }^{\prime}\right)}$. [24]

The score of a Bayesian network structure is expressed as

$$
D L(G, D)=D L_{\text {stru }}(G)+D L_{\text {tab }}(G)+D L_{\text {data }}(D \mid G) .
$$

In

$$
\left\{\begin{array}{l}
D L_{\text {stru }}(G)=\sum_{i=1}^{n}\left(\log n+\log \left(n, P a_{i}\right) \mid\right), \\
D L_{\text {tab }}(G)=\frac{1}{2} \sum_{i=1}^{n}\left|P a_{i}\right| *\left(r_{i}-1\right) \log N \\
D L_{\text {data }}(D \mid G)=N \sum_{i=1}^{n} H\left(X_{i} \mid P a_{i}\right) .
\end{array}\right.
$$

According to Bayesian principle $\log P(G \mid D)$, it is expressed as

$$
\log \left(G^{s} \mid D\right)=\log P\left(D \mid G^{s}\right)+\log P\left(G^{s}\right) .
$$

The approximate expression of the score obtained by the integral is

$$
\log (G \mid D) \approx \log P\left(D \mid \tilde{\theta}_{G}, G\right)-\frac{d}{2} \log N .
$$

This dimension is expressed for the Bayesian network as 
TABLe 1: Statistics of traditional teaching samples.

\begin{tabular}{lcccc}
\hline Class & Class size & Average (E) & Standard deviation & Mean standard error \\
\hline Experimental class & 42 & 68.67 & 15.422 & 2.380 \\
Control class & 42 & 67.69 & 15.045 & 2.322 \\
Standard class & 42 & 65.78 & 15.012 & 2.314 \\
\hline
\end{tabular}

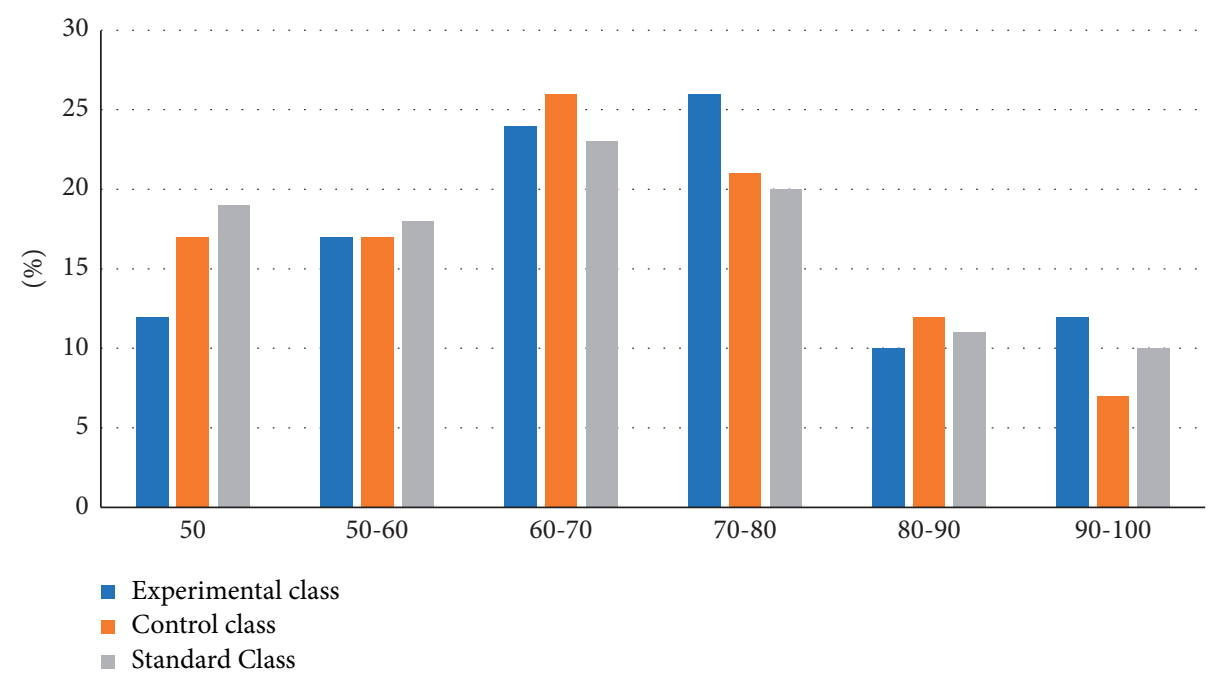

Figure 4: Traditional teaching mode results.

$$
d=\sum_{i=1}^{n}\left|P a_{i}\right|\left(\left|X_{i}\right|-1\right) .
$$

MCMC the algorithm transfers from the $i^{\text {th }}$ network structure $B s$ to the new network structure $B s$, the reception probability is [25]

$$
\begin{aligned}
\alpha\left(B s, B s^{\prime}\right) & =\min \left\{1, R_{\alpha}\right\}, \\
R_{\alpha} & =\frac{\#(\operatorname{nbd}(B s)) P\left(B s^{\prime} \mid D\right)}{\#\left(\operatorname{nbd}\left(B s^{\prime}\right)\right) P(B s|| D)} .
\end{aligned}
$$

\section{Simulation Experiment}

\subsection{Analysis of Student Performance}

4.1.1. Traditional Teaching Mode. The score analysis data are shown in Table 1 and Figure 4:

4.1.2. Network Multimedia Teaching Mode. The score analysis data are shown in Table 2 and Figure 5:

From Tables 1 and 2, we can see that the monthly test scores of the experimental class, the control class, and the standard class under the standard teaching mode are 68.67, 67.69 , and 65.78, respectively, and the scores under the network multimedia teaching mode are 73.50, 72.27, and 70.24 , respectively. The results of the online teaching model are generally higher than those of the traditional teaching model. Among them, the performance of the experimental class has a higher degree of increase, with an average increase of 4.83 , indicating that there are significant differences in the learning and cognitive abilities of students under different teaching models.

4.2. Analysis of Students' Knowledge Mastery. In order to test the students' mastery of knowledge under the two different teaching modes, we issued questionnaires to the students in the experimental class, the control class, and the standard class under the two different teaching modes, and compared the results obtained. The experimental conditions are shown in Figures 6 and 7.

From Figures 3 and4, we can see that under the traditional teaching mode, students have a low degree of knowledge mastery, with a complete mastery rate of only $15 \%$. Under the network multimedia teaching mode, the student's knowledge mastery rate has been greatly improved. The complete mastery rate is as high as $45 \%$, and the students' mastery of knowledge has been excellently improved, indicating that the network multimedia teaching mode can stimulate students' interest more in learning and improve learning efficiency.

4.3. Comparative Study of Teaching Design. Under the traditional teaching method, teachers generally use the textbooks issued by the school to teach. The traditional teaching methods will inevitably have some shortcomings. In the online teaching mode, the teacher will make the key content of the classroom into a PPT and display it in the classroom, which is not only convenient for the students, we understand the key points of the classroom, and it is also convenient for 
TABLE 2: Sample statistics of online teaching mode.

\begin{tabular}{lcccc}
\hline Class & Class size & Average (E) & Standard deviation & Mean standard error \\
\hline Experimental class & 42 & 73.50 & 11.677 & 1.756 \\
Control class & 42 & 72.27 & 14.357 & 2.215 \\
Standard class & 42 & 70.24 & 14.258 & 2.122 \\
\hline
\end{tabular}

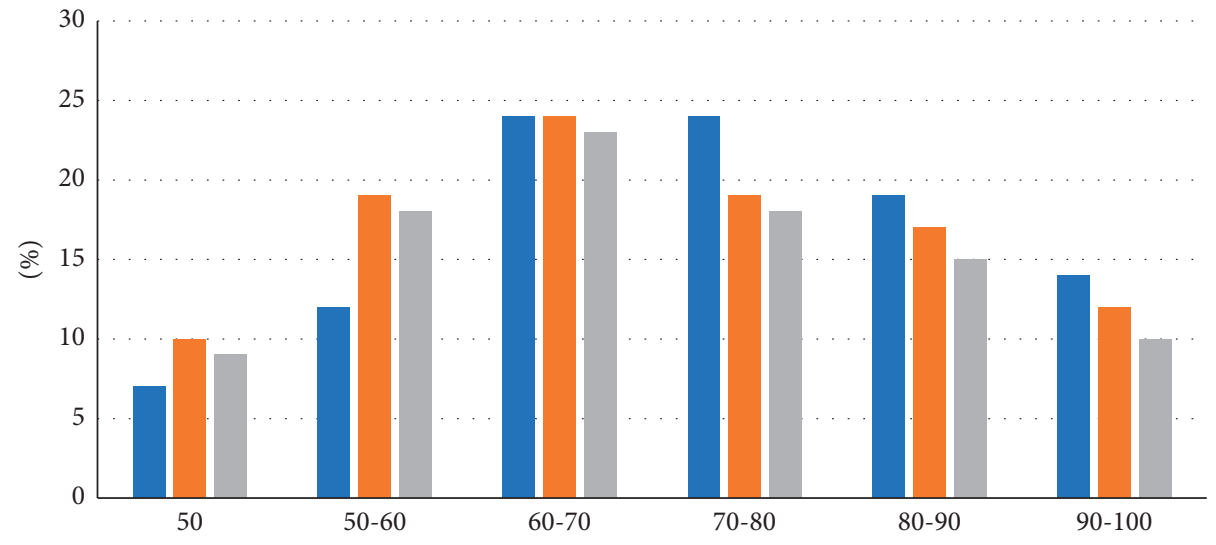

- Experimental class

- Control class

- Standard Class

Figure 5: Network multimedia teaching mode results.

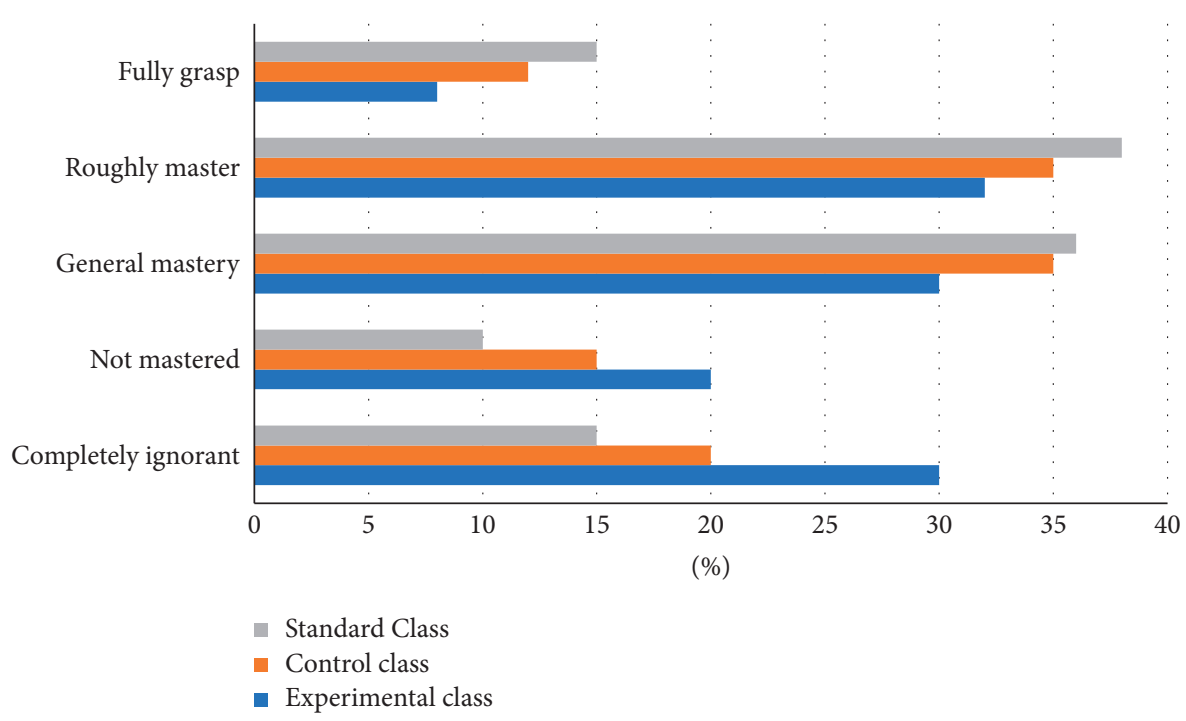

FIGURE 6: Knowledge mastery survey.

students to save and review later. In order to study the differences in the sources of teachers' lesson preparation resources, we have investigated the sources of lesson preparation resources of three different types of teachers, as shown in Table 3:

From the survey results in Table 3 and Figure 8, we can conclude that the three different types of teachers have the largest proportion of downloading course resources through the Internet; we have conducted research and investigation on whether to use courseware in class and the performance of students in class. The survey results are shown in Tables 4 and 5 .

From the research results in Figures 9 and 10, we can conclude that when multimedia teaching is not used, students' cooperation rate, classroom practice accuracy rate, and classroom completion rate are low. However, these 


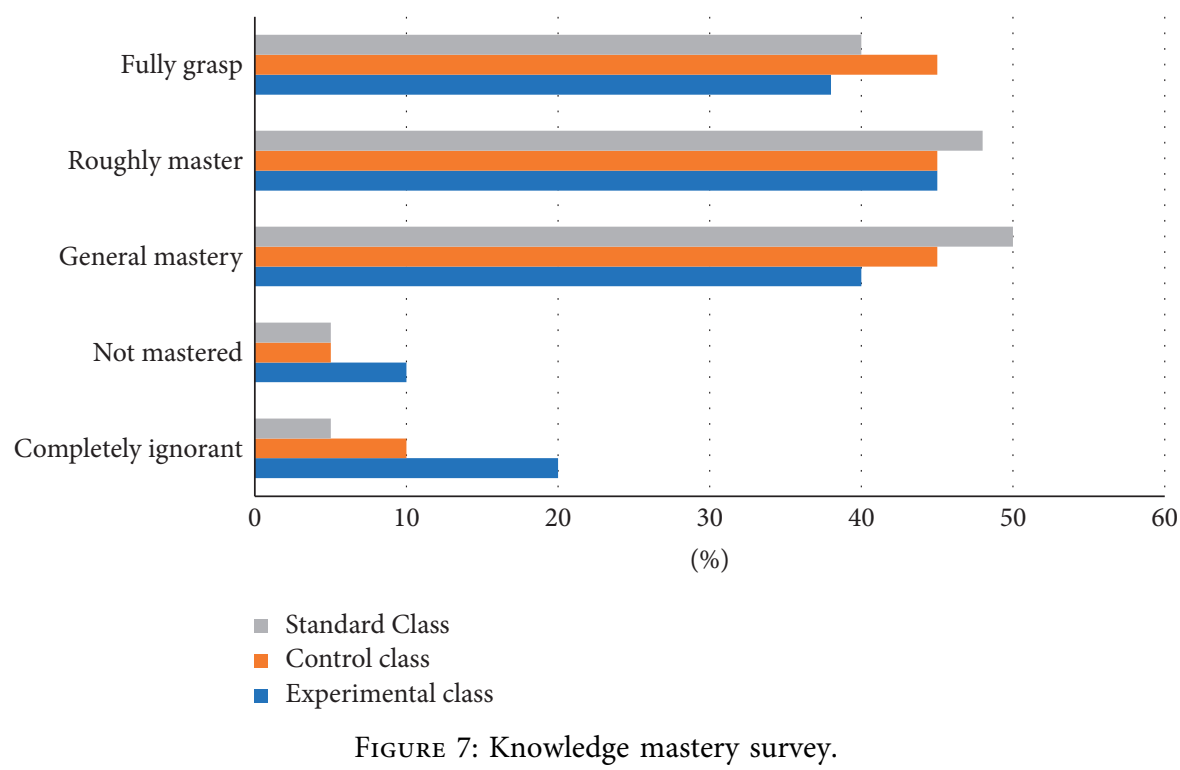

TABLE 3: Statistical table of sources of teaching resources.

\begin{tabular}{lccccc}
\hline & Excellent teacher lesson plan (\%) & Teaching reference (\%) & Online download (\%) & Write your own (\%) & Other (\%) \\
\hline Expert & 18.8 & 28.1 & 36.5 & 17.5 & 1.2 \\
Proficient & 16.7 & 27.2 & 40.1 & 15.6 & 2.6 \\
Novice & 26.2 & 35.7 & 46.7 & 11.9 & 2.4 \\
\hline
\end{tabular}

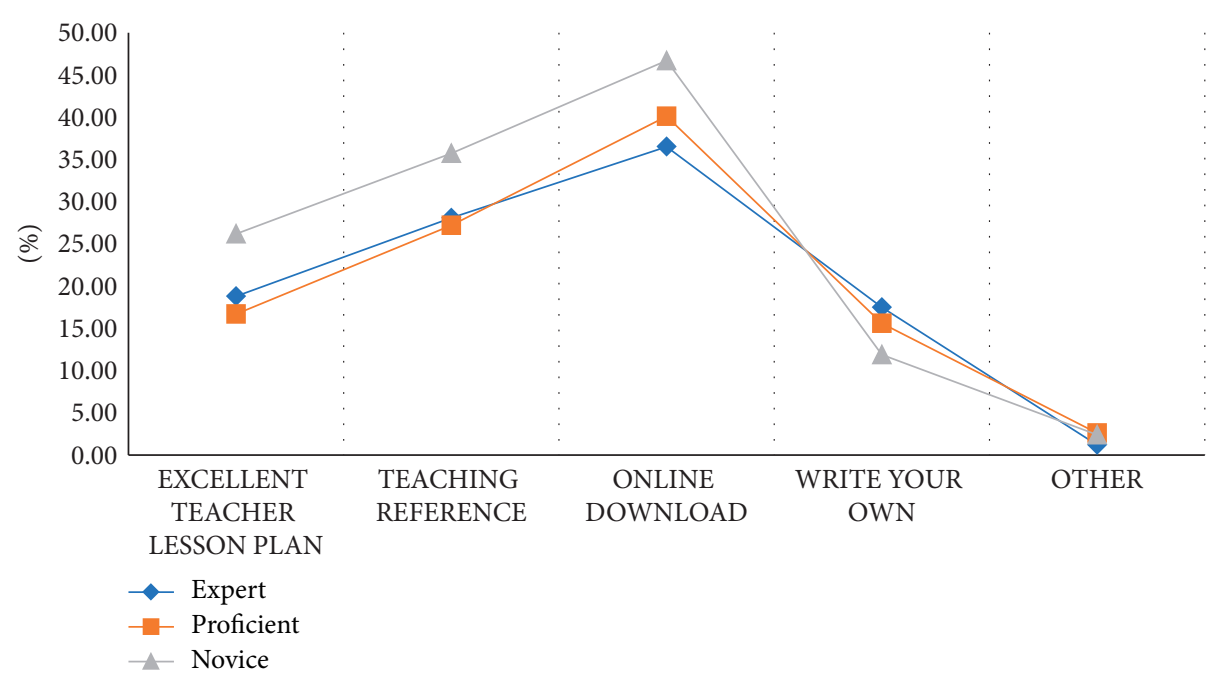

FIgURE 8: Statistics of sources of teaching resources.

problems have been improved after multimedia teaching is used. The cooperation rate of students and the accuracy of classroom exercises have been greatly improved. The accuracy rate of the experimental class is as high as $62.4 \%$, and the thinking ability of students has also been greatly improved. 
TABLE 4: Class performance without multimedia.

\begin{tabular}{lcccc}
\hline & $\begin{array}{c}\text { Students actively } \\
\text { cooperate (\%) }\end{array}$ & $\begin{array}{c}\text { Successfully complete the } \\
\text { teaching plan (\%) }\end{array}$ & $\begin{array}{c}\text { Classroom practice } \\
\text { accuracy (\%) }\end{array}$ & $\begin{array}{c}\text { Improve students' thinking } \\
\text { ability (\%) }\end{array}$ \\
\hline $\begin{array}{l}\text { Standard class } \\
\text { Control class }\end{array}$ & 11.5 & 6.3 & 30.6 & 13.5 \\
$\begin{array}{l}\text { Experimental } \\
\text { class }\end{array}$ & 12.1 & 16.7 & 35.2 & 15.9 \\
\hline
\end{tabular}

TABle 5: Use of multimedia classroom performance.

\begin{tabular}{lcccc}
\hline & $\begin{array}{c}\text { Students actively } \\
\text { cooperate (\%) }\end{array}$ & $\begin{array}{c}\text { Successfully complete the } \\
\text { teaching plan (\%) }\end{array}$ & $\begin{array}{c}\text { Classroom practice } \\
\text { accuracy (\%) }\end{array}$ & $\begin{array}{c}\text { Improve students' thinking } \\
\text { ability (\%) }\end{array}$ \\
\hline $\begin{array}{l}\text { Standard class } \\
\text { Control class }\end{array}$ & 22.5 & 16.9 & 41.6 & 23.5 \\
$\begin{array}{l}\text { Experimental } \\
\text { class }\end{array}$ & 35.1 & 27.6 & 55.3 & 17.9 \\
\hline
\end{tabular}

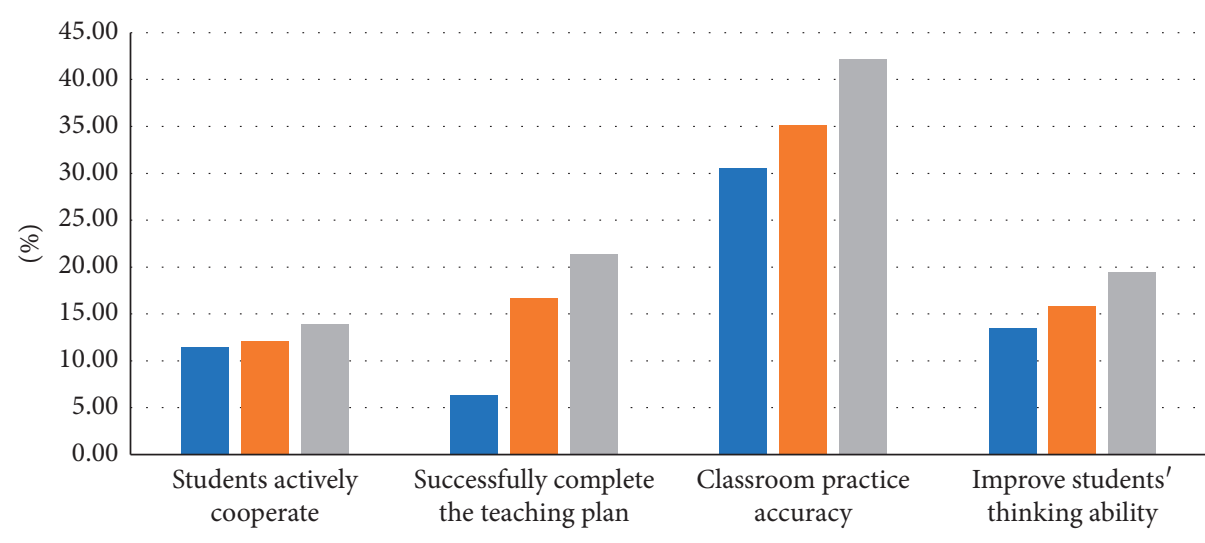

- Standard Class

- Control class

- Experimental class

FIGURE 9: Non-use of multimedia classroom performance statistics chart.

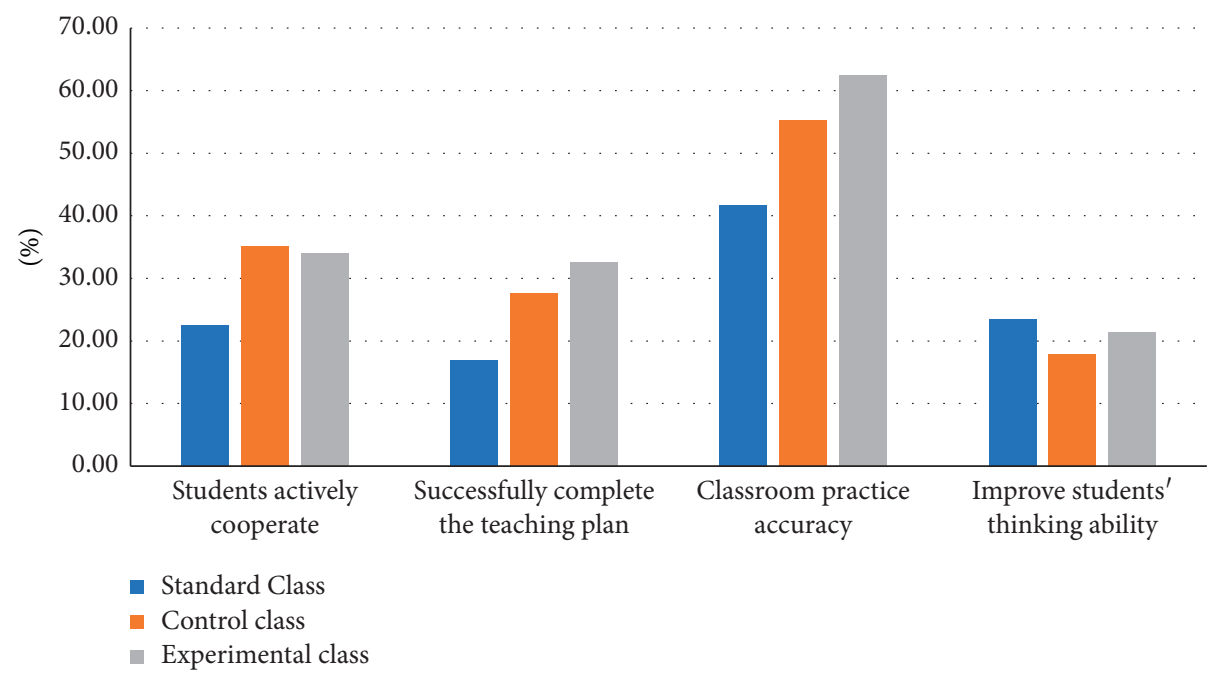

FIGURE 10: Using multimedia classroom performance statistics. 


\section{Conclusion}

Artificial intelligence empowers education reform, and the superiority of technology is vividly reflected. However, although all countries have achieved good results, the shortcomings of artificial intelligence empowerment are gradually exposed. In order to guide the development of artificial intelligence-enabled education, it is necessary to analyze the international experience and current problems and propose new directions for future artificial intelligenceenabled education. Make education fairness a reality and achieve the highest quality educational resources in the shortest time.

\section{Data Availability}

The experimental data used to support the findings of this study are available from the corresponding author upon request.

\section{Conflicts of Interest}

The author declares that there are no conflicts of interest regarding this work.

\section{References}

[1] X. N. Guo, "Analysis and exploration of computer teaching mode based on modern education technology," Computer Knowledge and Technology, vol. 23, no. 5, pp. 17-23, 2014.

[2] G. Liu, "The application of the mixed teaching mode based on SPOC in the course of education statistics and SPSS," Modern Information Technology, vol. 09, no. 12, pp. 141-167, 2018.

[3] Y. Wang, "Research on the construction and application of college smart classroom based on education informationization," in Proceedings of the 2018 8th International Conference on Education, Management, Computer and Society(EMCS 2018), pp. 258-262, Shenyang, China, December 2018.

[4] M. Veeramanickam, N. M. Sundaram, and L. S. Kumar, "Analysis of smart E-learning application based on various design aspects in IoT and ANN model," in Proceedings of the 2019 PhD Colloquium on Ethically Driven Innovation and Technology for Society (PhD EDITS), pp. 1-4, Bangalore, India, August 2019.

[5] F. Li, "The analysis of computer teaching mode based on modern educational technology," in Proceedings of the 2018 International Conference on Educational Research, Economics, Management and Social Sciences(EREMS 2018), pp. 11841188, Changchun, China, February 2018.

[6] X. Zhang, Y. Wang, and S. Sharma, "Design and analysis of flipped classroom experiment teaching based on DBR in information technology environment," International Journal of System Assurance Engineering and Management, vol. 09, no. 13, pp. 17-26, 2021.

[7] W. Jian, Z. Lu, W. Wu, and Y. Li, "The application of data mining technology based on teaching information," in Proceedings of the 2012 7th International Conference on Computer Science \& Education (ICCSE), pp. 652-657, IEEE, Melbourne, Australia, July 2012.

[8] J. Y. Zeng, "The research and application of smart campus system based on big data in data mining technology," Journal of Guiyang University (Natural Sciences), vol. 07, no. 20, pp. 17-21, 2018.

[9] L. Liu, "Analysis of college listening and speaking teaching mode based on network environment," Journal of Jilin Institute of Architecture \& Civil Engineering, vol. 06, no. 23, pp. 19-26, 2011.

[10] X. Xu, "Analysis on application mode of PBL teaching method based on experimental teaching platform," Experimental Technology and Management, vol. 8, no. 21, pp. 113-125, 2014.

[11] L. Wang, "An analysis of the application and limitation of information technology in education based on ihde's phenomenology of technology," Modern Distance Education Research, vol. 9, no. 4, pp. 105-113, 2012.

[12] B. Ge, "Analysis on professional integration of production and education personnel training mode in mobile application technology," vol. 08, no. 13, pp. 78-85, 2017.

[13] H. Zhao, Y. Fei, and C. Li, "Empirical analysis on aerobics multimedia teaching based on interactive mode," Applied Mechanics and Materials, vol. 380-384, pp. 2901-2905, 2013.

[14] J. Shao, "Innovative numerical control technology application teaching mode analysis," in Proceedings of the 2016 International Conference on Modern Education Technology (MET2016), pp. 589-594, Sanya, China, November 2016.

[15] C. Yu, "Research on the application mode of mobile learning in English education based on 4G technology," in Proceedings of the 2016 International Conference on Education, Sports, Arts and Management Engineering, pp. 5-9, Xi'an, China, March 2016.

[16] G. Chen, X. Xie, and S. Li, "Research on complex classification algorithm of breast cancer chip based on SVM-RFE gene feature screening," Complexity, vol. 2020, Article ID 1342874, 12 pages, 2020.

[17] B. He, "5G acceleration will drive economic output of 10.6 trillion yuan," Science Grand View Garden, vol. 07, no. 13, pp. 50-55, 2019.

[18] L. Li, "Research on the integration of $5 \mathrm{G}+\mathrm{VR}$ technology and ideological and political education-_taking the first VR ideological and political education training room in Jiangsu as an example," Education Modernization, vol. 6, no. 12, pp. 21-25, 2019.

[19] M. Sharples and J. Domingue, "The blockchain and kudos: a distributed system for educational record, reputation and reward,"vol. 9891, pp. 490-496, in Proceedings of the European Conference on Technology Enhanced Learning, vol. 9891, Springer, Lyon, France, September 2016.

[20] M. B. Hoy, "An introduction to the b and its implications for libraries and medicine," Medical Reference Services Quarterly, vol. 36, no. 3, pp. 273-279, 2017.

[21] D. J. Skiba, "The pb in education and health care," Nursing Education Perspectives, vol. 38, no. 4, pp. 220-221, 2017.

[22] C. F. Wu and L. P. Huang, "Developing the environment of information technology education using cloud computing infrastructure," American Journal of Applied Sciences, vol. 8, no. 9, pp. 864-871, 2011.

[23] X. Wang, G. Han, X. Du, and J. J. P. C. Rodrigues, "Mobile cloud computing in 5G: e," IEEE Network, vol. 29, no. 2, pp. 4-5, 2015.

[24] L. N. Tuan, H. M. Arif, I. Amirul, D. Y. Kim, Y. J. Choi, and Y. J. Men, "Survey of promising tech-nologies for $5 \mathrm{G}$ networks," Mobile Information Systems, vol. 08, no. 12, pp. 1-25, 2016.

[25] G. Sun, C.-C. Chen, and S. Bin, "Study of cascading failure in multisubnet composite complex networks," Symmetry Plus, vol. 13, no. 3, p. 523, 2021. 